\title{
The thymus is a common target in malnutrition and infection
}

\author{
Wilson Savino $^{1 *}$, Mireille Dardenne ${ }^{2}$, Licio A. Velloso ${ }^{3}$ and Suse Dayse Silva-Barbosa ${ }^{1,4}$ \\ ${ }^{1}$ Laboratory on Thymus Research, Oswaldo Cruz Institute, Oswaldo Cruz Foundation, Rio de Janeiro, Brazil \\ ${ }^{2}$ Hôpital Necker, Université René Descartes, CNRS UMR-8147, Paris, France \\ ${ }^{3}$ Department of Medicine, University of Campinas, Campinas, Brazil \\ ${ }^{4}$ Center for Bone Marrow Transplantation, National Cancer Institute, Rio de Janeiro, Brazil
}

Malnutrition, secondary to deficiency in intake of proteins, minerals or vitamins, consistently results in changes in the thymus. This organ undergoes a severe atrophy due to apoptosis-induced thymocyte depletion, particularly affecting the immature $\mathrm{CD} 4^{+} \mathrm{CD} 8^{+}$cells, as well as a decrease in cell proliferation. This feature is apparently linked to a hormonal imbalance, involving a decrease in leptin and consequent increase in glucocorticoid hormone levels in the serum. The thymic microenvironment is also affected in malnutrition: morphological changes in thymic epithelial cells have been found, together with a decrease of thymic hormone production by these cells. Additionally, intrathymic contents of extracellular proteins, such as fibronectin, laminin and collagens, are increased in thymuses from malnourished children. Taken together, these data clearly point to the notion that the thymus is significantly affected in malnutrition. Similar patterns of thymic changes occur in acute infectious diseases, including a severe atrophy of the organ, mainly due to the apoptosis-related depletion of immature $\mathrm{CD} 4^{+} \mathrm{CD} 8^{+}$thymocytes. Additionally, thymocyte proliferation is compromised in acutely-infected subjects. The microenvironmental compartment of the thymus is also affected in acute infections, with an increased density of the epithelial network and an increase in the deposition of extracellular matrix. In conclusion, it seems clear that the thymus is targeted in malnutrition as well as in acute infections. These changes are related to the impaired peripheral immune response seen in malnourished and infected individuals. Thus, strategies inducing thymus replenishment should be considered in therapeutic approaches, in both malnutrition and acute infectious diseases.

\section{The relationship between thymus, the immune system and malnutrition}

It has been a long time since scientists noticed that, in the context of the malnutrition-related immunodeficiency, the thymus undergoes a variety of alterations, comprising, among others, a severe atrophy ${ }^{1}$. This is so consistent that the thymus has been considered as a barometer of malnutrition ${ }^{2}$. Interestingly, such thymic atrophy can also be found in a variety of infectious diseases $^{3}$. Considering that in many countries malnutrition frequently parallels infections, these two pathological situations likely cause profound alterations in the host's immune system, likely in part as a consequence of targeting the thymus. Herein we will review the similarities concerning the changes seen in the thymus of individuals suffering from malnutrition and/or infectious diseases. Nevertheless, before compiling and discussing these data, it is worthwhile to provide a general background of the normal thymus structure and function, including the thymic microenvironmental compartment and its role in intrathymic $\mathrm{T}$ cell differentiation.

\section{The thymic microenvironment and its role in T-cell differentiation}

The thymus is a primary lymphoid organ, in which bone marrow-derived T-cell precursors undergo differentiation, ultimately leading to migration of positively selected thymocytes to the $\mathrm{T}$ cell-dependent areas of peripheral lymphoid organs. Such a process involves sequential expression of various proteins and rearrangements of the T-cell receptor (TCR) genes. Most immature thymocytes express neither the TCR complex nor the CD4 or CD8 accessory molecules; such cells are termed double-negative thymocytes, and they represent $5 \%$ of total thymocytes. Maturation progresses with the acquisition of CD4 and CD8 markers, generating the $\mathrm{CD} 4{ }^{+} \mathrm{CD}^{+}$double-positive cells, which comprise $80 \%$ of the whole population. In this stage, TCR genes are rearranged, and productive rearrangements yield the membrane expression of the TCR (complexed with the CD3) in low densities $\left(\mathrm{TCR}^{\text {low }}\right)$. Thymocytes that do not undergo a productive TCR gene rearrangement die by apoptosis, whereas those expressing productive TCR will interact with peptides presented by molecules of the major histocompatibility complex (MHC), expressed on microenvironmental cells. This interaction will determine the positive and negative selection events, crucial for normal thymocyte differentiation.

Negative selection results in apoptosis-mediated cell death. Positively selected thymocytes progress to the mature $\mathrm{TCR}^{\text {high }} \mathrm{CD}^{+} \mathrm{CD}^{-}$or $\mathrm{TCR}^{\text {high }} \mathrm{CD} 4{ }^{-} \mathrm{CD}^{+}$single positive stage, comprising $15 \%$ of thymocytes that ultimately leave the organ to form the large majority of the peripheral $\mathrm{T}$ cell repertoire ${ }^{4}$. Thymocyte differentiation occurs as cells migrate 
within the thymic lobules: $\mathrm{TCR}^{-} \mathrm{CD}^{-} \mathrm{CD}^{-}$and $\mathrm{TCR}^{+} \mathrm{CD} 4^{+-}$ $\mathrm{CD}^{+}$are cortically located, whereas mature $\mathrm{TCR}^{+} \mathrm{CD} 4^{+-}$ $\mathrm{CD}^{-}$and $\mathrm{TCR}^{+} \mathrm{CD} 4^{-} \mathrm{CD}^{+}$cells are found in the medulla. Along this journey, thymocytes interact with various components of the thymic microenvironment, a three-dimensional network formed of thymic epithelial cells (TEC), macrophages, dendritic cells, fibroblasts and extracellular matrix components. In addition to the key interaction, involving the TCR/peptide$\mathrm{MHC}$, in the context of CD8 or CD4 molecules, the thymic microenvironment influences thymocyte maturation via adhesion molecules and extracellular matrix (ECM); interactions that are relevant for thymocyte migration ${ }^{5,6}$. Moreover, microenvironmental cells modulate thymocyte differentiation by soluble polypeptides, comprising: a) cytokines, such as interleukin (IL)-1, IL-3, IL-6, IL-7, IL-8 and stem cell factor; b) chemokines and c) thymic hormones, including thymulin, thymopoietin and thymosin- $\alpha 1^{4}$.

\section{Phenotypic and functional changes of thymocytes in} malnutrition and acute infectious diseases

As stated above, one of the most conspicuous changes in malnutrition is thymic atrophy (Fig. 1). This phenomenon is largely due to massive thymocyte death: the main phenotypic feature of this depletion is the loss immature $\mathrm{CD} 4^{+} \mathrm{CD} 8^{+}$ cells ${ }^{1}$. In addition to the increase in thymocyte death seen in thymuses from malnourished individuals, thymocyte proliferation seems to be affected, since the numbers of thymic cells labelled with proliferating cell nuclear antigen (PCNA) marker are diminished in malnourished rats ${ }^{7}$. Thus, the overall malnutrition-related thymocyte depletion seems to result from enhanced thymocyte death plus decreased thymocyte proliferation. It is important to highlight that the major change in the thymic lymphoid compartment is also observed in humans suffering from malnutrition: a severe thymic atrophy with cortical thymocyte depletion is a consistent finding in necropsies of malnourished subjects ${ }^{1,8}$. Indeed, by means of echography, atrophy of the organ has also been observed in vivo in malnourished children'. Importantly, a study conducted in Guinea-Bissau revealed that thymus size at birth was associated with infant mortality ${ }^{10}$. Nevertheless, malnutrition-associated thymic atrophy seems to be reversible if appropriate diet is provided. This concept emerges from an interesting longitudinal study carried out on severely malnourished Bolivian children that were under refeeding ${ }^{11}$. In this study thymus size was assessed weekly by mediastinal ultrasound scanning. Compared to controls, the malnourished group had severe involution of the thymus, a significantly higher proportion of circulating immature $\mathrm{T}$ lymphocytes and a lower proportion of mature T lymphocytes. After two months of diet rehabilitation, the thymic area was recovered.

Severe thymic atrophy is also a common feature in acute infections, also reflecting intense lymphocyte depletion, particularly of cortical thymocytes bearing the phenotype $\mathrm{CD}^{+}{ }^{+} \mathrm{CD}^{+}$(Fig. 1, Table 1). This has been shown in a variety of infections, such as AIDS, rabies, malaria, Chagas disease and schistosomiasis, among others ${ }^{3}$. In some cases, thymocyte loss is so severe that the cortical region of thymic lobules virtually disappears, as a consequence of the severe $\mathrm{CD}^{+}{ }^{+} \mathrm{CD} 8^{+}$thymocyte depletion ${ }^{3}$.
Another similarity to what is seen in malnutrition, the proliferative response of thymocytes is also reduced in acutely infected individuals. We found a significant decrease in both concanavalin A- and anti-CD3-driven proliferative responses in murine Chagas disease and this outcome was paralleled by a decrease in IL-2 production $^{12}$.

\section{Thymocyte depletion associated with specific deficiencies in} vitamins and trace elements: the zinc-deficiency paradigm

In addition to protein-related malnutrition, mineral and vitamin deficiencies cause thymic atrophy, with cortical thymocyte depletion $^{13-16}$. Moreover, in iron-deficient mice, a decrease in mitogen-induced proliferative response of thymocytes has been demonstrated ${ }^{13}$.

Many of the effects of protein-calorie malnutrition on immune function are well recognized to result in associated alterations in mineral and/or vitamin metabolism, able to affect the immune system directly ${ }^{17}$. In this regard, the abnormal incidence of various infections and the existence of lymphopaenia and lymphoid organ atrophy in malnourished children have been repeatedly demonstrated and evidence points to zinc insufficiency as being central to this type of immunodeficiency ${ }^{18}$.
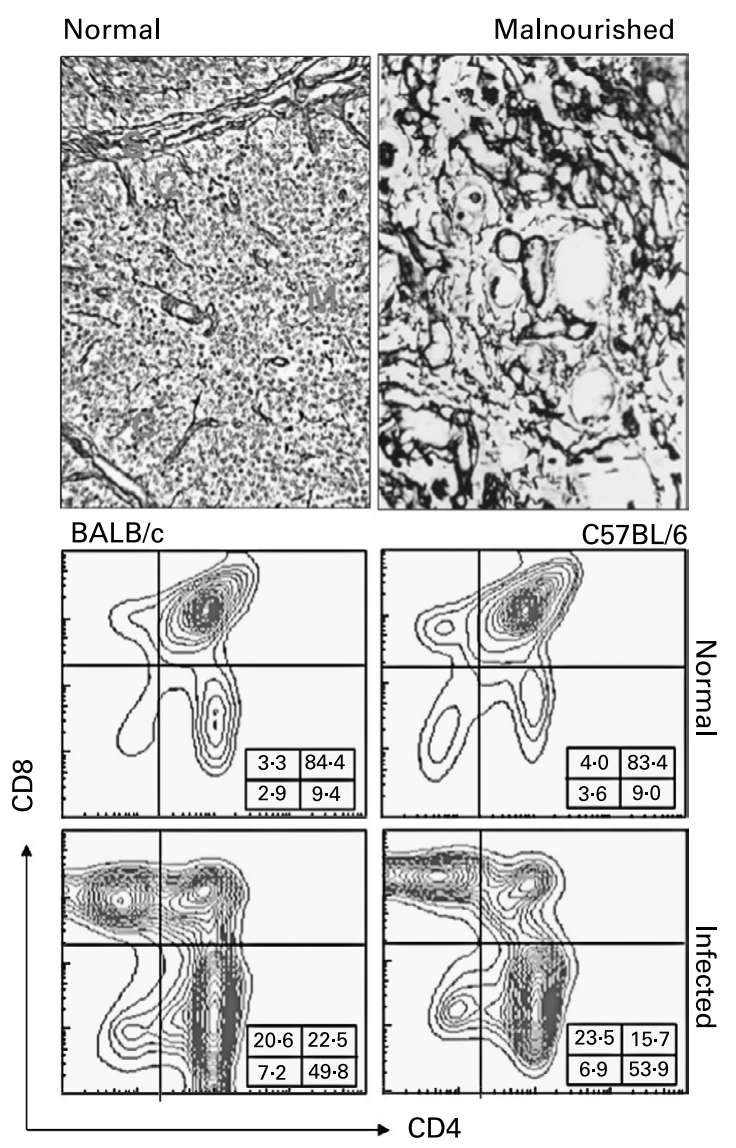

Fig. 1. Thymic atrophy in human malnutrition and experimental acute Chagas disease. Upper panel shows reticulin staining to show the increase in the extracellular matrix network seen in atrophic thymus from a malnourished child, as compared to a normal age-matched pattern. The bottom panels show the typical CD4/CD8-defined cytofluorometric profiles of thymocytes from normal or Trypanosoma cruzi-acutely infected mice. Note the large reduction in the proportions of $\mathrm{CD} 4^{+} \mathrm{CD} 8^{+}$thymocyte subset. 
Table 1. Thymic atrophy in human and experimental infectious diseases*

\begin{tabular}{llcccc}
\hline Infectious disease & Type of infectious agent & Cortical atrophy (Histology) & $\mathrm{CD}^{+} \mathrm{CD}^{+}$thymocyte depletion & Human data & Animal data \\
\hline AIDS & HIV & + & + & + & + \\
Rabies & Rabies virus & + & + & ND \\
Measles & Measles virus & + & + & + \\
Hepatitis & Hepatitis virus & ND & + & + & + \\
Chagas disease & Trypanosoma cruzi & + & + & + & + \\
Malaria & Plasmodium chabaudi & + & ND & ND \\
Paracocciodosis & Paracoccidioides brasiliensis & + & ND & + \\
Schistosomiasis & Schistosoma mansoni & + & ND & + \\
\hline
\end{tabular}

${ }^{*}$ Modified from ${ }^{3}$. ND, not determined.

Zinc plays a major role in cell division, differentiation, apoptosis and gene transcription, and strongly influences the immune system affecting primarily $\mathrm{T}$ cells ${ }^{19}$. Studies of the effects of severe zinc deficiency in several species, including humans, report substantial thymic atrophy as well as accelerated lymphopaenia, leading to a reduction in cell and antibody-mediated responses, thus influencing the susceptibility to infectious diseases $^{20-22}$. Early observations showed that mice maintained on a zinc deficient diet develop a progressive thymic involution: after 4 weeks the thymus retains only $25 \%$ of its original size and at 6 weeks, only a few thymocytes remain in the organ ${ }^{23}$. Such changes are observed mostly in the thymic cortex, with severe loss of $\mathrm{CD}^{+}{ }^{+} \mathrm{CD}^{+}$thymocytes, and can be reversed by zinc supplementation $^{24,25}$. Moreover, marginal zinc deficiency, in the early post-natal period, also results in substantial reduction in thymic size $\mathrm{e}^{26}$.

The mechanism(s) of heightened apoptosis in zinc deficient mice remain(s) to be precisely determined. However, glucocorticoid hormones seem to be involved, since zinc deficiency yields a chronic stimulation of corticosterone production ${ }^{27}$, and adrenalectomy prevents thymic atrophy secondary to zinc deficiency.

Although these studies have been performed in animal models, they raise concern about the impact of cell death in humans who are deficient in zinc due to suboptimal diets or chronic diseases ${ }^{28}$. Nutritional supplementation might be considered in chronically ill patients with compromised immune defense, as in the case of AIDS patients ${ }^{29,30}$. In these subjects, zinc supplementation resulted in a significant increase in $\mathrm{CD}^{+}{ }^{+}$cells and a decreased mortality. This notion can also be applied in patients with Chagas disease, since they exhibit a decrease in serum zinc concentrations ${ }^{31}$; the same being observed in a variety of haemopoietic organs of infected rats $^{32}$. Accordingly, severity of experimental Chagas disease is much higher in zinc-deficient mice ${ }^{33}$.

\section{The hormonal control of thymocyte depletion in malnutrition and acute infections}

It is now well established that the physiology of the thymus (including both lymphoid and microenvironmental compartments) is under neuroendocrine control ${ }^{4}$. In this context, it is conceivable that distinct pathological states in the organism (i.e. malnutrition and acute infectious diseases) can affect such a hormonal influence upon the thymus. Circulating levels of glucocorticoids increase in protein malnourished mice, as compared to age-matched controls. Additionally, implanted corticosterone-containing pellets, capable of generating serum glucocorticoid levels equivalent to those found in malnourished mice, are sufficient to yield thymocyte depletion ${ }^{34}$. As discussed below, leptin also seems to be involved.

Leptin plays a complex and wide-ranging role in the regulation of physiological events that respond to the nutritional status in mammals ${ }^{35}$. Initially, leptin was described as a soluble factor that informs the hypothalamus about the energy stores in peripheral tissues, particularly about white adipose tissue. In this organ, leptin is produced and secreted in direct proportion to the total mass of adipose tissue of the organism $^{36}$. By acting predominantly in hypothalamic neurons located in the arcuate nucleus, leptin controls neurotransmitter production and release, which leads to reduction of food intake and stimulation of energy expenditure by thermogenesis $^{35}$. Additionally, some humans and rodents lacking proper leptin production or to express defective leptin receptors, bear a certain degree of immunodeficiency characterized by reduced T-cell proliferative response to various mitogens, impaired production of IL-4, and inappropriate antibody production after immunization ${ }^{35,37,38}$. Interestingly, leptin/leptin receptor deficient animals exhibit atrophy of lymphoid tissues, particularly the thymus, and such a defect can be reversed by the reposition of the hormone ${ }^{39}$.

Since malnutrition leads simultaneously to thymic atrophy and hypoleptinaemia, a mechanistic role for insufficient leptin action in the thymus of malnourished subjects was proposed $^{40}$, taking into account that leptin has been shown to prevent starvation-induced thymic atrophy ${ }^{39,41}$.

At least two mechanisms may play a role in leptin-induced inhibition of thymic atrophy: increase of thymopoiesis and inhibition of apoptosis ${ }^{42,43}$. Thymopoiesis has been tested in wild-type C57BL/6 and BALB/c mice, in endotoxin-stressed (LPS treated) BALB/c mice, and in leptin deficient obese (ob/ob) mice ${ }^{42}$. Leptin is actually able to increase thymopoiesis, but only in leptin-deficient mice or in animals treated with LPS, suggesting that it acts as a thymopoietic factor only in the setting of induced thymic atrophy ${ }^{42}$. Although this hypothesis has not been tested in malnutrition models, results obtained from starved animals suggest that a similar phenomenon may occur in the thymus of malnourished subjects ${ }^{39}$. On the other hand, inhibition of apoptosis has been evaluated in wild-type Wistar rats. Short-term leptin treatment significantly reduces thymocyte apoptosis. This outcome seems to occur predominantly by leptin acting upon $\mathrm{CD} 4{ }^{+} \mathrm{CD} 8^{+}$cells undergoing maturation, since highest expression of the corresponding receptor is seen at the thymocyte differentiation 


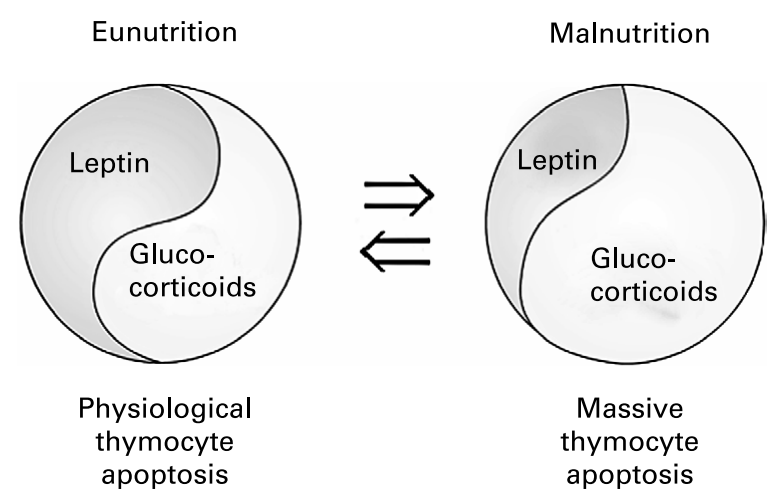

Fig. 2. Putative hormonal circuit involved in triggering the depletion of thymocytes that occurs in malnourished individuals. In physiological conditions there is a balance (herein illustrated by the Chinese Yin/Yang symbol of equilibrium) between glucocorticoids (pro-apoptotic) and leptin (anti-apoptotic), accounting for the normal pattern of thymocyte apoptosis. In malnutrition, there is a decrease in leptin levels, leading to a stimulation of the hypothalamus-pituitary-adrenal axis that results in increased circulating levels of glucocorticoid hormones (upper arrow), which in turn enhance thymocyte apoptosis. As indicated by the bottom arrow, this situation can be reversed by the re-establishment of an appropriate diet (modified from ${ }^{40}$ ).

stage $^{43}$. Interestingly, the anti-apoptotic effect of leptin in the thymus is not mediated by the classic JAK2/STAT3 signaling pathway, but rather depends on the activation of the docking protein IRS $-1^{43}$.

Thus, leptin is one possible mediator of malnutrition-induced thymic atrophy. Actually, it is conceivable that under situations of malnutrition, the imbalance between leptin production (which is decreased) and glucocorticoid hormone levels (which are increased) is at least partially responsible for thymocyte depletion and consequent atrophy of the organ (see figure 2). In this respect, it will be worthwhile to test whether this hormone can be applied as a therapeutic tool to partially prevent the harmful effects of malnutrition upon the immune system.

The precise mechanisms responsible for the thymic atrophy seen in acute infections are not completely elucidated, and may vary in distinct diseases. But similar to malnutrition, one major pathway is related to the rise in serum glucocorticoid hormone levels, a classical component of the stress response of the organism to the infection. Thymocyte depletion commonly observed in rabies virus infected mice ${ }^{44}$ can be prevented by adrenalectomy prior to infection. In murine Chagas disease, we also found high levels of corticosterone, in both acutely and chronically infected animals ${ }^{45,46}$. Nevertheless, adrenalectomy alone did not prevent Trypanosoma cruzi-induced cortical thymocyte depletion. More recently, it was demonstrated that complete inhibition of glucocorticoid receptors by in vivo injection of RU-486, did succeed in preventing thymocyte depletion following acute Trypanosoma cruzi infection ${ }^{47}$. Whether such a procedure modifies leptin levels in acutely-infected mice, remains to be determined, and represents an interesting open field of investigation.

\section{The thymic microenvironment in malnutrition and acute infections}

In addition to the lymphoid compartment, the thymic microenvironment is affected under various malnutrition and infectious conditions. Morphological changes in the thymic epithelium from protein-malnourished mice include an increase, both in cortical and medullary thymic epithelial cells (TEC), of intracytoplasmic accumulations of large, circular, homogeneously electron-dense profiles, rich in free and esterified cholesterol ${ }^{48}$. Conversely, these lipid-laden epithelial cells cannot exhibit the membrane-bound cytoplasmic vacuoles observed in control animals, and that normally contain the thymic hormone thymulin ${ }^{4}$. By means of morphometry, the volume of the epithelial tissue in the cortex and medulla of thymuses from malnourished mice has been shown to be decreased, as compared to well-nourished control animals ${ }^{48}$. Unfortunately, no data were reported concerning TEC death in this experimental model.

\section{Decreased thymic endocrine function in malnourished and acutely-infected individuals}

One functional parameter that has been evaluated under malnutrition conditions is thymic hormone production by TEC. Protein-malnourished mice exhibit abnormally low levels of circulating thymulin ${ }^{1,49}$, and this is also observed in protein-malnourished rats and humans ${ }^{50}$. Even in humans suffering from calorie malnutrition secondary to anorexia nervosa, low thymulin serum levels have been reported ${ }^{51}$. Furthermore, decreased serum thymulin levels have been reported in mice submitted to diets designed to trigger deficiency in zinc, iron, or vitamins ${ }^{1,13,52}$,. At least regarding zinc deficiency, similar results have been found in humans ${ }^{53}$. It is noteworthy that the concept of decreased thymic hormone in malnutrition is not restricted to thymulin, since it was also reported for thymopoietin production ${ }^{54}$. In this study, the authors further showed that prenatal undernutrition was significantly associated with reduced thymopoietin production in interaction with the duration of exclusive breast-feeding. These findings provide support for the importance of foetal and early infant programming of thymic function, and longterm implications for the immune system, and consequently adult disease risk.

In severe infection conditions, thymic endocrine function is also affected. We observed in Trypanosoma cruzi-infected mice a transient decrease in the serum levels of the thymic hormone thymulin ${ }^{55}$. In human HIV infection a consistent and long-term decrease of thymulin secretion has also been documented, in terms of serum levels and intrathymic contents of the hormone ${ }^{56-58}$.

\section{Increased extracellular matrix in the thymus of malnourished children}

In addition to the abnormalities shown in TEC, cells from the thymus of malnourished children exhibit a further microenvironmental alteration, namely, an increase in the deposition of extracellular matrix (ECM) proteins. We studied by histological, ultrastructural, and immunohistochemical means thymuses obtained in necropsies from malnourished children. We observed a consistent increase in the intralobular ECMcontaining network, which could be ascertained histologically by the dense reticulin staining. This abnormally dense ECM network contained fibronectin, laminin, and type IV collagen. Importantly, the enhancement of thymic ECM in malnourished individuals positively correlated with the degree of thymocyte depletion ${ }^{8}$. This correlation may represent a 
cause-effect relationship in which the contact of thymocytes with abnormally high amounts of thymic ECM triggers and/ or enhances programmed cell death. However, this notion is still hypothetical, demanding experimental demonstration. Similar changes in thymic ECM were observed in glucocorticoid-hormone treated mice and TEC cultures ${ }^{4}$, leading to hypothesis that the enhanced ECM deposition seen in malnutrition may be also related to high levels of serum glucocorticoid hormones. Such an alteration was also seen in acute infections, as exemplified by experimental Chagas disease $^{55,59}$. In this infection model, changes in ECM were accompanied by alterations in the migratory response of thymocytes, with abnormal export of $\mathrm{CD}^{+}{ }^{+} \mathrm{C}^{+}$immature thymocytes, some of them having bypassed the normal selective selection process ${ }^{59-61}$. Whether similar cell migration abnormalities exist in malnourished subjects, is still to be elucidated.

\section{Concluding remarks}

The various issues discussed above clearly show that the thymus is a common target organ in malnutrition and in acute infections. The changes summarized herein likely have consequences, leading to the impaired peripheral immune response shown in both malnourished and infected individuals. Thus, strategies to promote thymus replenishment should be considered when designing therapeutic approaches, in both malnutrition and acute infectious diseases.

\section{Conflict of interest statement}

This work was partially funded with grants from Fiocruz, CNPq and Fapesp (Brazil), CNRS (France). No author has any conflict of interest to declare.

\section{References}

1. Chandra RK (1992) Protein-energy malnutrition and immunological responses. J Nutr 122, Suppl 3, 597-600.

2. Prentice AM (1999) The thymus: a barometer of malnutrition. Br J Nutr 81, 345-347.

3. Savino W (2006) The thymus is a common target organ in infectious diseases. PLoS Pathogens 2, 472-483.

4. Savino W \& Dardenne M (2000) Neuroendocrine control of thymus physiology. Endocrine Rev 21, 412-443.

5. Savino W, Mendes da Cruz DA, Silva JS, Dardenne M \& Cotta de Almeida V (2002) Intrathymic T cell migration: a combinatorial interplay of extracellular matrix and chemokines? Trends Immunol 23, 305-313.

6. Savino W, Mendes-da-Cruz DA, Smaniotto S, Silva-Monteiro E \& Villa-Verde DMS (2004) Control of thymocyte migration: an interplay of distinct cellular interactions. J Leukocyte Biol 75, 951-961.

7. Mitsumori K, Takegawa K, Shimo T, Onodera H, Yasuhara K \& Takahashi M (1996) Morphometric and immunohistochemical studies on atrophic changes in lympho-hematopoietic organs of rats treated with piperonyl butoxide or subjected to dietary restriction. Arch Toxicol 70, 809-814.

8. Lyra JS, Madi K, Maeda CT \& Savino W (1993) Thymic extracellular matrix in human malnutrition. J Pathol 171, 231-236.

9. Parent G, Chevalier P, Zalles L, Sevilla R, Bustos M, Dhenin J \& Jambon B (1994) In vitro lymphocyte-differentiating effects of thymulin (Zn-FTS) on lymphocyte subpopulations of severely malnourished children. Am J Clin Nutr 60, 274-278.

10. Aaby P, Marx C, Trautner S, Rudaa D, Hasselbach H, Jensen H \& Lisse I (2002) Thymus size at birth is associated with infant mortality: a community study from Guinea Bissau. Acta Pediatr 91, 698-703.

11. Chevalier P, Sevilla R, Zalles L, Sejas E, Belmonte G, Parent G \& Jambon B (1996) Immuno-nutritional recovery of children with severe malnutrition. Santé 6, 201-208.

12. Leite-de-Moraes MC, Minoprio P, Dy M, Dardenne M, Savino W \& Hontebeyrie-Joskowicz M (1994) Endogenous IL-10 and IFN$\gamma$ production controls thymic cell proliferation in mice acutely infected by Trypanosoma cruzi. Scand J Immunol 39, 51-58.

13. Kuvibidila S, Dardenne M, Savino W \& Lepault F (1990) Influence of iron-deficiency anemia on selected thymus functions in mice: thymulin biological activity, T-cell subsets, and thymocyte proliferation. Am J Clin Nutr 51, 228-232.

14. Dhur A, Galan P, Christides JP, Polier de Courcy G, Preziosi P \& Hercberg S (1991) Effect of folic acid deficiency upon lymphocyte subsets from lymphoid organs in mice. Comp Biochem Physiol A 98, 235-240.

15. Malpuech-Brugere C, Nowacki W, Gueux E, Kuryszko J, Rock E, Rayssiguier Y \& Mazur A (1999) Accelerated thymus involution in magnesium-deficient rats is related to enhanced apoptosis and sensitivity to oxidative stress. Br J Nutr 81, 405-411.

16. Nodera M, Yanagisawa H \& Wada O (2001) Increased apoptosis in a variety of tissues of zinc-deficient rats. Life Sci $\mathbf{6 9}$, 1639-1649.

17. Cunningham-Rundles S, McNeeley DF \& Moon A (2005) Mechanisms of nutrient modulation of the immune response. J Allergy Clin Immunol 115, 1119-1128.

18. Shankar AH \& Prasad AS (1998) Zinc and immune function: the biological basis of altered resistance to infection. Am J Clin Nutr 68, 447S-463S.

19. Chesters J (1977) Zinc. In Hankbook of Nutritionally Essential Mineral Elements, pp. 185-230 [B Odel, R Sunde and EDS, editors]. New York: Marcel Dekker.

20. Fraker P, King L, Garvy B \& Medina C (1993) Immunopathology of zinc deficiency: a role for apoptosis. In Human Nutrition: a comprehensive treatise, pp. 267-283 [DM Klurfeld, editor]. New York, NY: Plenum Press.

21. Kuvibidila S, Yu L, Ode D \& Warrier RP (1993) The immune response in protein-energy malnutrition and single nutrient deficiencies. In Human Nutrition: a comprehensive treatise, pp. 121-157 [DM Klurfeld, editor]. New York: Plenum Press.

22. Fraker P, King L, Laakko T \& Vollmer T (2000) The dynamic link between the integrity of the immune system and zinc status. J Nutr 130, 1399-1406.

23. Fernandes G, Nair N, Once K, Tanaka T, Floyd R \& Good R (1979) Impairment of cell mediated immunity function in dietary zinc deficiency in mice. Proc Natl Acad Sci USA 76, 457-461.

24. Fraker PJ, Depascale-Jardieu R, Zwickl CM \& Luecke RW (1978) Regeneration of T-cell helper function in zinc-deficient adult mice. Proc Natl Acad Sci USA 75, 5660-5664.

25. King LE, Osati-Ashtiani F \& Fraker PJ (2002) A distinct role for apoptosis in the loss of precursor lymphocytes during zinc deficiency. J Nutr 132, 974-979.

26. Beach RS, Gershwin ME \& Hurley LS (1979) Altered thymic structure and mitogen responsiveness in postnatally zincdeprived mice. Dev Comp Immunol 3, 725-738.

27. Fraker P, Osati-Ashtiani F, Wagner MA \& King LE (1995) Possible roles for glucocorticoids and apoptosis in the suppression of lymphopoiesis during zinc deficiency: a review. $J \mathrm{Am}$ Coll Nutrition 14, 11-17.

28. Fraker PJ (2004) Roles for cell death in zinc deficiency. $J$ Nutr 135, 359-362. 
29. Baum M, Shor-Posner G \& Campa A (2000) Zinc status in human immunodeficiency virus infection. J Nutr 130, 1421S-1423S.

30. Baum M, Campa A, Lai S, et al. (2003) Zinc status in human immunodeficiency virus type 1 infection and illicit drug use. Clin Infect Dis 37, 117-123.

31. Burguera JL, Burguera M, Alarcon OM, Canada de Zunzunegui M, Carrasco HA, Davila D \& Reinosa J (1988) Concentration changes of zinc, copper and iron in serum of chronic chagasic myocardiopathic patients. J Trace Elem Electrolytes Health Dis 2, 215-219.

32. Matousek de Abel de la Cruz AJ, Burguera AJ, Burguera M \& Anez N (1993) Changes in total content of iron, copper and zinc in serum, heart, liver, spleen and skeletal muscle tissues of rats infected with Trypanosoma cruzi. Biol Trace Elem Res 37, 51-70.

33. Fraker PJ, Caruso R \& Kierszenbaum F (1982) Alteration of the immune and nutritional status of mice by synergy between zinc deficiency and infection with Trypanosoma cruzi. J Nutr 112, 1224-1229.

34. Barone KS, O'Brien PC \& Stevenson JR (1993) Characterization and mechanisms of thymic atrophy in protein-malnourished mice: role of corticosterone. Cell Immunol 148, 226-233.

35. Munzberg H \& Myers MG Jr (2005) Molecular and anatomical determinants of central leptin resistance. Nat Neurosci 8, 566-570.

36. Friedman JM (2002) The function of leptin in nutrition, weight, and physiology. Nutr Rev 60, S1-14; discussion S68-84, 85-87.

37. Lord GM, Matarese G, Howard JK, Baker RJ, Bloom SR \& Lechler RI (1998) Leptin modulates the T-cell immune response and reverses starvation-induced immunosuppression. Nature 394, 897-901.

38. Farooqi IS, Matarese G, Lord GM, et al. (2002) Beneficial effects of leptin on obesity, $\mathrm{T}$ cell hyporesponsiveness, and neuroendocrine/metabolic dysfunction of human congenital leptin deficiency. J Clin Invest 110, 1093-1103.

39. Howard JK, Lord GM, Matarese G, Vendetti S, Ghatei MA, Ritter MA, Lechler RI \& Bloom SR (1999) Leptin protects mice from starvation-induced lymphoid atrophy and increases thymic cellularity in ob/ob mice. J Clin Invest 104, 1051-1059.

40. Savino W (2002) The thymus gland is a target in malnutrition. Eur J Clin Nutr 56, Suppl 3, S46-S49.

41. Mito N, Yoshino H, Hosoda T \& Sato K (2004) Analysis of the effect of leptin on immune function in vivo using diet-induced obese mice. J Endocrinol 180, 167-173.

42. Hick RW, Gruver AL, Ventevogel MS, Haynes BF \& Sempowski GD (2006) Leptin selectively augments thymopoiesis in leptin deficiency and lipopolysaccharide-induced thymic atrophy. J Immunol 177, 169-176.

43. Mansour E, Pereira FG, Araujo EP, et al. (2006) Leptin inhibits apoptosis in thymus through a janus kinase-2-independent, insulin receptor substrate-1/phosphatidylinositol-3 kinase-dependent pathway. Endocrinology 147, 5470-5479.

44. Cardenas-Palomo LF, de Souza-Matos DC, Chaves-Leal E, Bertho AL \& Marcovistz R (1995) Lymphocyte subsets and cell proliferation analysis in rabies-infected mice. J Clin Lab Immunol 46, 49-61.

45. Corrêa-de-Santana E, Paez-Pereda M, Theodoropoulou M, Gruebler Y, Nihei OK, Bozza M, Arzt E, Villa-Verde DMS, Renner U, Stalla J, Stalla GK \& Savino W (2006) Hypothalamus-pituitary-adrenal axis during Trypanosoma cruzi acute infection in mice. J Neuroimmunol 173, 12-22.
46. Leite-de-Moraes MC, Hontebeyrie-Joskowicz M, Leboulanger F, Savino W, Dardenne M \& Lepault F (1991) Studies on the thymus in Chagas' disease. II. Thymocyte subset fluctuations in Trypanosoma cruzi-infected mice: relationship to stress. Scand J Immunol 33, 267-275.

47. Roggero E, Pérez AR, Tamae-Kakazu M, Piazzon I, Nepomnaschy I, Besedovsky H, Bottasso O \& del Rey A (2006) Endogenous glucocorticoids cause thymus atrophy but are protective during acute Trypanosoma cruzi infection. J Endocrinol 190, 495-503.

48. Mittal A \& Woodward B (1985) Thymic epithelial cells of severely undernourished mice: accumulation of cholesteryl esters and absence of cytoplasmic vacuoles. Proc Soc Exp Biol Med 178, 385-391.

49. Mittal A, Woodward B \& Chandra RK (1988) Involution of thymic epithelium and low serum thymulin bioactivity in weanling mice subjected to severe food intake restriction or severe protein deficiency. Exp Mol Pathol 48, 226-235.

50. Jambon B, Ziegler O, Maire B, Hutin MF, Parent G, Fall M, Burnel D \& Duheille J (1988) Thymulin (facteur thymique serique) and zinc contents of the thymus glands of malnourished children. Am J Clin Nutr 48, 335-342.

51. Wade S, Bleiberg F, Mosse A, Lubetzki J, Flavigny H, Chapuis P, Roche D, Lemonnier D \& Dardenne M (1985) Thymulin ( $\mathrm{Zn}$-facteur thymique serique) activity in anorexia nervosa patients. Am J Clin Nutr 42, 275-280.

52. Dardenne M, Savino W, Wade S, Kaiserlian D, Lemonnier D \& Bach JF (1984) In vivo and in vitro studies of thymulin in marginally zinc-deficient mice. Eur J Immunol 14, 454-458.

53. Prasad AS, Meftah S, Abdallah J, Kaplan J, Brewer GJ, Bach JF \& Dardenne M (1988) Serum thymulin in human zinc deficiency. J Clin Invest 82, 1202-1210.

54. McDade TW, Beck MA, Kuzawa CW \& Adair LS (2001) Prenatal undernutrition and postnatal growth are associated with adolescent thymic function. J Nutr 131, 1225-1231.

55. Savino W, Leite de Moraes MC, Hontebeyrie-Joskowicz M \& Dardenne M (1989) Studies on the thymus in Chagas' disease. I. Changes in the thymic microenvironment in mice acutely infected with Trypanosoma cruzi. Eur J Immunol 19, 1727-1733.

56. Dardenne M, Bach JF \& Safai B (1983) Low serum thymic hormone levels in patients with acquired immunodeficiency syndrome. $N$ Engl J Med 309, 48-49.

57. Incefy GS, Pahwa S, Pahwa R, Sarngadharan MG, Menez R, et al. (1986) Low circulating thymulin-like activity in children with AIDS and AIDS-related complex. AIDS Res 2, 109-116.

58. Savino W, Dardenne M, Marche C, Trophylme D, Dupui JM, Pekovic D \& Bach JF (1986) Thymic epithelium in AIDS: an immunohistologic study. Am J Pathol 122, 302-307.

59. Cotta de Almeida V, Mendes da Cruz DA, Bonomo A \& Savino W (2003) Acute Trypanosoma cruzi infection modulates intrathymic contents of extracellular matrix ligands and receptors and alters thymocyte migration. Eur J Immunol 33, 2439-2448.

60. Mendes-da-Cruz DA, Silva JS, Cotta-de-Almeida V \& Savino W (2006) Altered thymocyte migration during experimental acute Trypanosoma cruzi infection: combined role of fibronectin and the chemokines CXCL12 and CCL4. Eur J Immunol 36, 1486-1493.

61. Savino W, Villa-Verde DMS, Mendes-da-Cruz DA, Silva-Monteiro E, et al. (2007) Cytokines and cell adhesion receptors in the regulation of immunity to Trypanosoma cruzi. Cytokine \& Growth Factor Rev 18, 107-124. 